\title{
STUDI KELAYAKAN LOKASI RENCANA PELETAKAN JACK-UP DRILLING RIG MENGGUNAKAN HASIL PENCITRAAN SIDE SCAN SONAR
}

\author{
Sindi Mandasari, Yuwono \\ Program Studi Teknik Geomatika FTSP-ITS, Kampus ITS Sukolilo, Surabaya, 60111 \\ Email : rrmandasari@ymail.com, yuwono@geodesy.its.ac.id
}

\begin{abstract}
Abstrak
Sumber daya minyak bumi yang tersebar di beberapa wilayah perairan di negara kita ini mempunyai nilai ekonomis yang sangat tinggi. Dibutuhkan sebuah perencanaan detil untuk meletakkan media eksplorasi (jack-up drilling rig) untuk memanfaatkan sumber daya minyak bumi. Oleh sebab itu, untuk mengetahui kelayakan lokasi peletakan jackup drilling rig diperlukan suatu survai agar tidak membahayakan rig tersebut ketika memasuki lokasi pengeboran. Dalam hal ini dibutuhkan suatu gambaran dari dasar laut sehingga perlu dilakukan survai perencanaan yang mencakup pemetaan kedalaman laut serta kenampakan permukaan dasar laut.

Penelitian ini menggunakan hasil pencitraan side scan sonar yang didukung oleh data batimetri, data pasut dan data GPS untuk mengetahui kondisi dari permukaan dasar laut. Dari hasil survai tersebut didapatkan informasi yang dapat digunakan untuk mengetahui kelayakan lokasi rencana peletakkan jack-up drilling rig agar tidak membahayakan rig tersebut ketika masuk dan dioperasikan.

Hasil dari penelitian ini menunjukkan bahwa lokasi rencana peletakan jack-up drilling rig masih dapat dikatakan layak dimana permukaan dasar laut daerah penelitian tersebut sebagian besar didominasi dengan tanah lempung atau lanau. Pada daerah penelitian terdapat cukup banyak jack-up footprint dan ditemukan banyak goresan pada permukaan dasar laut, pipa bawah laut, serta sedimen yang cukup keras (coarse sediment). Jack-up drilling rig hendaknya masuk melalui sisi timur dari platform.
\end{abstract}

Kata Kunci : Side Scan Sonar, Jack-Up Drilling Rig, Permukaan Dasar Laut (Seabed Surface)

\section{PENDAHULUAN}

\section{Latar Belakang}

Sumber daya minyak bumi yang tersebar di beberapa wilayah perairan di negara kita ini mempunyai nilai ekonomis yang sangat tinggi. Untuk memanfaatkan sumber daya minyak bumi tersebut diperlukan suatu perencanaan untuk peletakan media eksplorasi minyak bumi yang disebut jack-up drilling rig. Untuk mengetahui kelayakan lokasi peletakan jack-up drilling rig diperlukan suatu survai agar tidak membahayakan rig tersebut ketika memasuki lokasi pengeboran. Dalam hal ini dibutuhkan suatu gambaran dari dasar laut sehingga perlu dilakukan survai perencanaan yang mencakup pemetaan kedalaman laut serta kenampakan permukaan dasar laut.

Penelitian ini menggunakan hasil pencitraan side scan sonar yang didukung oleh data batimetri, data pasut dan data GPS untuk mengetahui kondisi dari permukaan dasar laut. Dari hasil survai tersebut didapatkan informasi yang dapat digunakan untuk mengetahui kelayakan lokasi rencana peletakkan jack-up drilling rig agar tidak membahayakan rig tersebut ketika masuk dan dioperasikan.

\section{Rumusan Permasalahan}

Perumusan masalah dalam penelitian ini adalah : "Bagaimana kondisi permukaan dasar laut (seabed surface) yang didapat dari hasil pencitraan side scan sonar untuk digunakan sebagai referensi kelayakan lokasi rencana peletakan jack-up drilling rig?"

\section{Batasan Masalah/Ruang Lingkup}

Adapun batasan masalah yang diajukan dalam penelitian ini adalah sebagai berikut:

1. Lokasi penelitian Tugas Akhir ini berada di Provinsi Jawa Barat, yaitu di Laut Jawa dengan koordinat antara $\left(6^{\circ} 4^{\prime} 39,87^{\prime \prime}\right.$ - 6 $\left.4^{\circ} 47,86^{\prime \prime}\right)$ LS

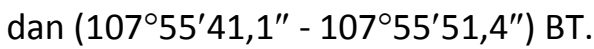


2. Data yang digunakan merupakan hasil pencitraan side scan sonar dari daerah penelitian tersebut.

3. Kelayakan lokasi rencana peletakan jack-up drilling rig ini hanya didasarkan pada interpretasi pencitraan side scan sonar dan didukung dengan data dari singlebeam echosounder.

4. Hasil pengolahan data side scan sonar adalah peta kondisi permukaan dasar laut yang didukung oleh data dari singlebeam echosounder sebagai representasi dari kedalaman laut (peta batimetri).

5. Kelayakan lokasi rencana peletakan jack-up drilling rig hanya ditinjau dari kondisi permukaan dasar laut.

6. Area studi kasus merupakan area yang pernah dimasuki jack-up driliing rig sebelumnya.

\section{Tujuan}

Tujuan penelitian ini untuk mengetahui kondisi permukaan dasar laut berdasarkan hasil pencitraan side scan sonar untuk dijadikan rekomendasi kelayakan lokasi rencana peletakan jack-up drilling rig agar tidak membahayakan rig tersebut ketika memasuki area pengeboran dan saat beroperasi.

\section{Manfaat}

Manfaat penelitian yang diperoleh dari penelitian ini adalah untuk mengetahui kondisi permukaan dasar laut (seabed surface) sehingga dapat dijadikan suatu rekomendasi untuk peletakan jack-up drilling rig pada eksplorasi sumber daya minyak bumi.

\section{METODOLOGI PENELITIAN}

\section{Lokasi Penelitian}

Lokasi penelitian Tugas Akhir ini berada di Provinsi Jawa Barat, yaitu di Laut Jawa dengan koordinat antara $\left(6^{\circ} 4^{\prime} 39,87^{\prime \prime}-6^{\circ} 4^{\prime} 47,86^{\prime \prime}\right)$ LS dan $\left(107^{\circ} 55^{\prime} 41,1^{\prime \prime}-107^{\circ} 55^{\prime} 51,4^{\prime \prime}\right)$ BT.

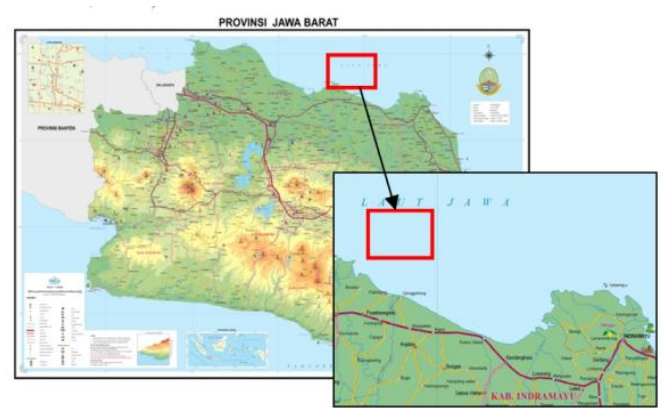

Gambar 1. Lokasi Penelitian

\section{Data Dan Peralatan}

\section{Data}

Data yang digunakan dalam penelitian ini adalah:

1. Data side scan sonar (Cmax) dari daerah penelitian

2. Data GPS daerah penelitian

3. Data singlebeam echosounder (Odom Echotrack) daerah penelitian yang sudah dikoreksi dengan heave compensator

4. Data pasang surut perairan tersebut.

\section{- Peralatan}

Peralatan yang digunakan dalam penelitian ini adalah:

1. Perangkat Keras (Hardware)
a. Laptop

2. Perangkat Lunak (Software)

a. Triton Suite

b. AutoCAD Map 3D 2008

c. Microsoft Office 2007 (Ms. Excel dan Ms. Word) 


\section{Pengolahan Data}

Adapun untuk diagram alir pengolahan data adalah sebagai berikut:

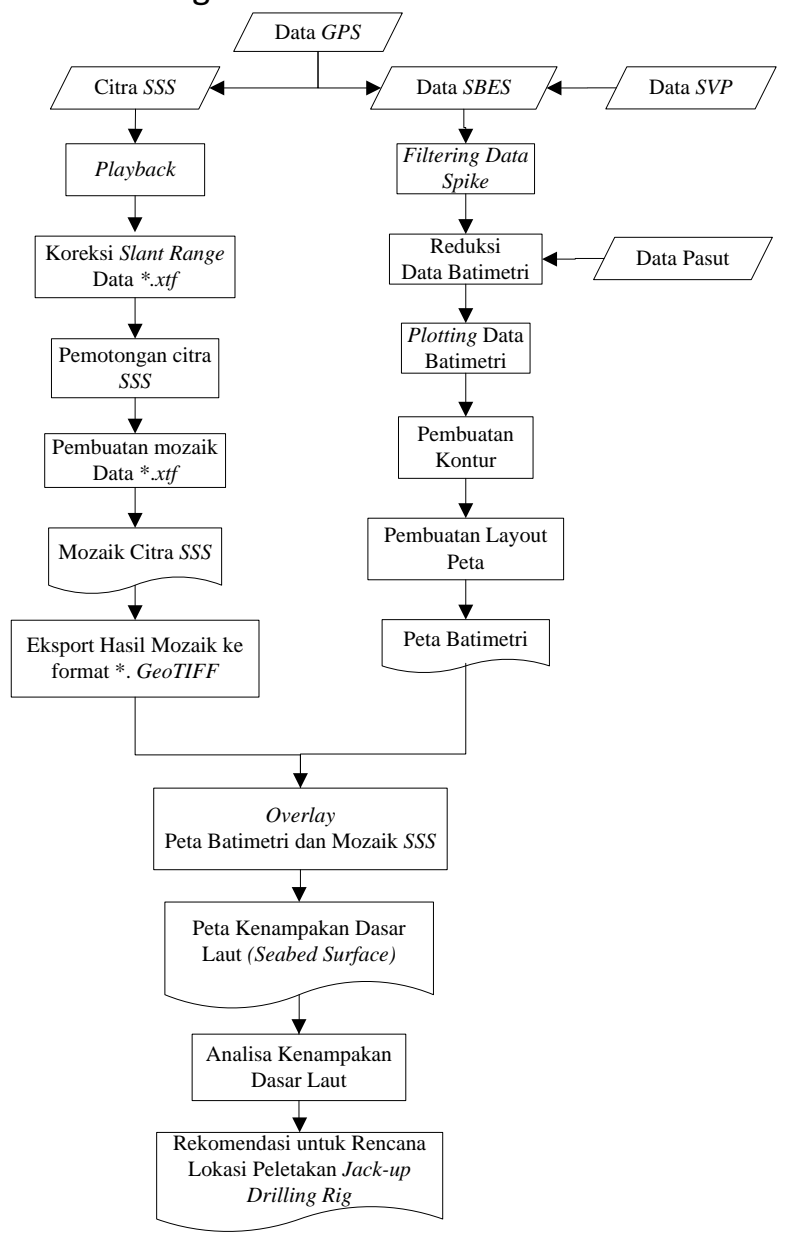

Gambar 2. Diagram Alir Pengolahan Data

Penjelasan dari diagram alir tersebut adalah sebagai berikut :

a. Data GPS adalah data yang diperoleh dari hasil survai yang telah diatur agar berjalan simultan dengan alat side scan sonar dan singlebeam echosounder. Data yang diperoleh diakusisikan dengan software, sehingga didapat koreksi posisi secara diferensial $(X, Y)$ dan data vertikal berupa kedalaman dasar laut $(z)$ didapatkan dari alat SBES (singlebeam echosounder).

b. Data side scan sonar ditampilkan ulang (playback) untuk memastikan bahwa data tersebut dalam kondisi baik (tidak error).

c. Koreksi jarak miring (slant range) ditujukan untuk mengkoreksi jarak miring pada citra side scan sonar sehingga jarak yang didapat merupakan jarak datar. d. Pemotongan citra (cropping) ditujukan untuk menghilangkan bagian citra yang hasilnya kurang baik.

e. Pembuatan mozaik dilakukan untuk mendapatkan gambaran permukaan dasar laut secara menyeluruh

f. Mozaik yang didapat kemudian diinterpretasi untuk mendapatkan sifat fisik material dan bentuk objek, baik dengan mengetahui bentuk (shape), derajat kehitaman (hue saturation), atau ukuran (size) dari objek atau target. Selain itu, digunakan interpretasi berdasarkan karakteristik gelombang akustik sonar yang di terima. Gelombang yg diterima akan mencerminkan karakteristik dari dasar laut itu sendiri.

g. Data dari singlebeam echosounder diolah dengan cara menghilangkan data spike (anomali data yang disebabkan oleh gerakan kapal, adanya makhluk hidup yang tidak sengaja melintas di jalur survai, dan sebagainya).

h. Data batimetri yang sudah dikoreksi data spike-nya kemudian reduksi dengan data pasut wilayah perairan tersebut.

i. Data batimetri yang dihasilkan kemudian di plot dan dilanjutkan dengan pembuatan kontur batimetri sehingga menghasilkan suatu peta batimetri.

j. Mozaik yang didapat dari citra side scan sonar kemudian di-overlay dengan peta batimetri sehingga menghasilkan peta kenampakan dasar laut (seabed surface).

k. Analisa kenampakan dasar laut ditujukan untuk mengetahui bagaimana kondisi permukaan dasar laut tersebut sehingga dihasilkan suatu rekomendasi apakah daerah tersebut layak untuk rencana peletakan jackup drilling rig.

\section{HASIL DAN PEMBAHASAN}

\section{Survai Batimetri}

Pada penelitian kali ini, peta batimetri yang dihasilkan adalah peta batimetri yang dibuat berdasarkan data yang diperoleh dari SBES (single beam echosounder). Peta batimetri tersebut digabungkan dengan peta kenampakan permukaan dasar laut dengan skala 1:2500. 


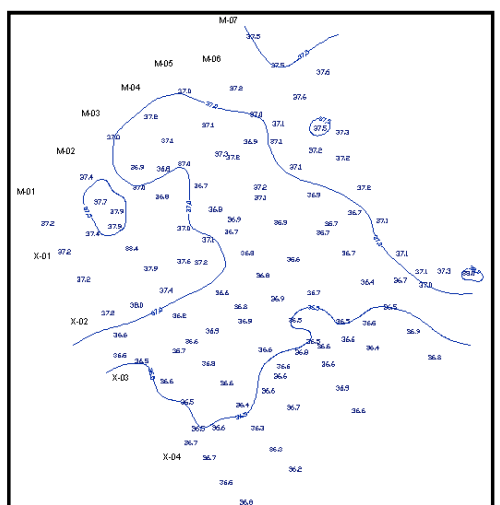

Gambar 3. Hasil Survai Batimetri

\section{Mozaik Citra Side Scan Sonar}

Mozaik citra side scan sonar merupakan gabungan dari beberapa citra side scan sonar yang dapat menggambarkan bagaimana kondisi permukaan dasar laut. Mozaik tersebut merupakan hasil koreksi interpretasi citra side scan sonar pada tiap lajur utama dan lajur silang yang saling bertampalan.

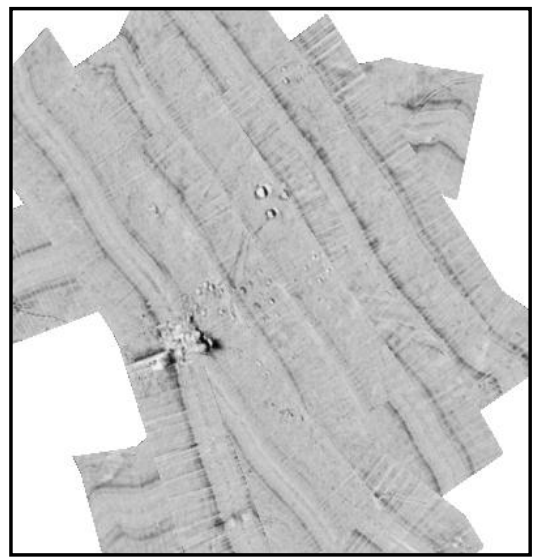

\section{Gambar 4. Hasil Mozaik Citra Side Scan Sonar}

Peta kenampakan permukaan dasar laut didapat melalui proses pertampalan (overlay) antara hasil mozaik pencitraan side scan sonar dengan peta batimetri daerah survai. Dari peta tersebut dapat diketahui data posisi $(\mathrm{x}, \mathrm{y})$ serta kedalaman (z) serta informasi tentang obyek-obyek yang ada pada permukaan dasar laut. Peta tersebut dibuat dengan skala 1:2500. Hasil dari penelitian ini adalah peta kenampakan permukaan dasar laut.

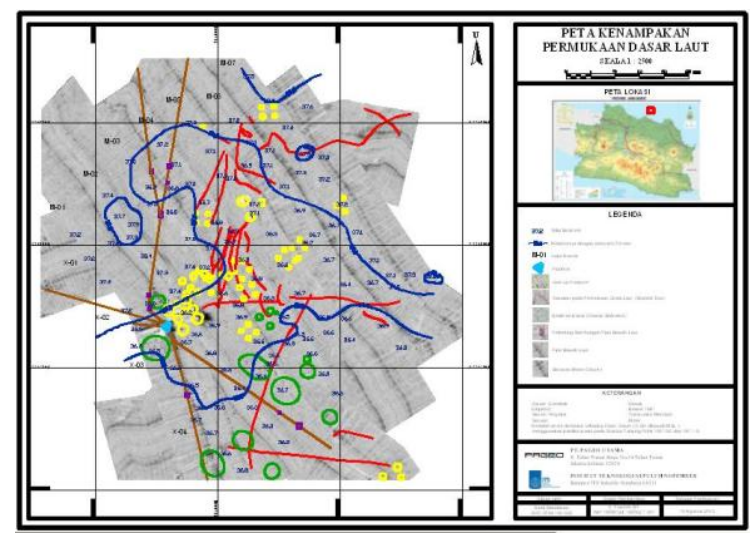

Gambar 5. Peta Kenampakan Permukaan Dasar Laut

\section{ANALISA}

\section{Analisa Hasil Survai Batimetri}

Pada penelitian kali ini, peta batimetri yang dihasilkan kurang maksimal, hal tersebut dikarenakan data batimetri yang diambil merupakan data yang didapat dari SBES (single beam echosounder), sehingga data yang didapat hanya merupakan data kedalaman dari lajur survai. Oleh sebab itu, peta batimetri yang dihasilkan kurang dapat menggambarkan bagaimana kondisi topografi dari permukaan dasar laut.

Hasil survai batimetri yang didapat menunjukkan bahwa kedalaman daerah survai berkisar antara 36,2 - 38,9 meter. Nilai kedalaman tersebut menunjukkan bahwa daerah penelitian mempunyai bentuk topografi yang cenderung landai karena tidak terdapat perbedaan yang terlalu signifikan pada nilai kedalaman yang didapat. Nilai kedalaman daerah survai semakin ke utara cenderung semakin dalam, akan tetapi hal tersebut tidak terlalu menjadi masalah karena selisih kedalamnnya hanya berkisar antara 1-2 meter.

\section{Analisa Hasil Pencitraan Side Scan Sonar}

Kondisi permukaan dasar laut pada area survai ini cenderung berwarna terang. Hal tersebut menunjukkan bahwa permukaan dasar laut diinterpretasi sebagai lempung atau lempung lanau dengan tingkat kekerasan cukup lunak. Pada permukaan dasar laut juga terlihat adanya beberapa jack-up footprint disekitar platform, garukan permukaan dasar laut yang disebabkan 
oleh kaki jack-up drilling rig, serta beberapa area sedimen yang cukup keras (coarse sediment). Selain itu, disisi kiri daerah penelitian juga terdapat pipa bawah laut sehingga perlu diwaspadai agar tidak membahayakan proses peletakan jack-up drilling rig.

Adapun hasil interpretasi permukaan dasar laut dari daerah penelitian adalah sebagai berikut.

Tabel 1. Hasil Interpretasi Jack-up Footprint

\begin{tabular}{|c|c|c|c|c|c|}
\hline \multirow{2}{*}{ No. } & \multirow{2}{*}{$\begin{array}{l}\text { Jack-up } \\
\text { Footprint }\end{array}$} & \multicolumn{2}{|c|}{$\begin{array}{c}\text { Koordinat Titik Pusat } \\
(\mathrm{m})\end{array}$} & \multirow{2}{*}{$\begin{array}{l}\text { Diameter } \\
\text { (m) }\end{array}$} & \multirow{2}{*}{ Gambar } \\
\hline & & $\mathbf{x}$ & $\mathbf{Y}$ & & \\
\hline \multirow[t]{4}{*}{1} & A1 & 384089,408 & 9334782,994 & 8,963 & \\
\hline & $\mathrm{A} 2$ & 384114,242 & 9334785,451 & 9,210 & \\
\hline & A3 & 384116,346 & 9334766,041 & 9,551 & \\
\hline & A4 & 384091,153 & 9334763,967 & 10,891 & \\
\hline 2 & B1 & 383968,215 & 9334741,543 & 8,457 & \\
\hline \multirow[t]{3}{*}{3} & $\mathrm{C} 1$ & 384050,580 & 384050,580 & 20,447 & \\
\hline & $\mathrm{C}_{2}$ & 384089,318 & 9334587,426 & 13,847 & \\
\hline & C3 & 384066,296 & 9334556,984 & 16,341 & \\
\hline
\end{tabular}

Tabel 2. Hasil Interpretasi Coarse Sediment

\begin{tabular}{|c|c|c|c|c|c|}
\hline \multirow{2}{*}{ No. } & \multirow{2}{*}{$\begin{array}{c}\text { Coarse } \\
\text { Sediment }\end{array}$} & \multicolumn{2}{|c|}{$\begin{array}{c}\text { Koordinat Titik Pusat } \\
(\mathrm{m})\end{array}$} & \multirow{2}{*}{$\begin{array}{c}\text { Radius } \\
\text { (m) }\end{array}$} & \multirow{2}{*}{ Gambar } \\
\hline & & $\mathrm{x}$ & $\mathbf{Y}$ & & \\
\hline 1 & A & 383877863 & 9334384782 & 2639 & \\
\hline 2 & B & 383877,863 & 9334384,782 & 55,33 & \\
\hline 3 & $\mathrm{C}$ & 384076,281 & 9334254,117 & 56,08 & \\
\hline 4 & D & 384138,032 & 9334203,089 & 56,52 & \\
\hline
\end{tabular}

Analisa Kelayakan Lokasi Rencana Peletakan Jack-Up Drilling Rig

Hal yang perlu diperhatikan ketika akan meletakan jack-up drilling rig pada lokasi pengeboran adalah terkait dengan kondisi permukaan dasar laut. Dalam penelitian kali ini dilakukan penginterpretasian kondisi dasar laut menggunakan hasil pencitraan side scan sonar untuk memastikan apakah daerah penelitian tersebut benar-benar bersih (site clearance) pada permukaan dasar lautnya.
Lokasi penelitian merupakan lokasi yang sudah pernah dilakukan pengeboran menggunakan jackup drilling rig, sehingga disarankan lokasi peletakan kaki jack-up menggunakan posisi yang sama sesuai dengan bekas jejak kaki jack-up drilling rig (jack-up footprint) sebelumnya.

Terkait dengan syarat dan kondisi permukaan dasar laut itu sendiri, maka dapat disimpulkan bahwa daerah penelitian merupakan daerah yang masih dapat dikatakan layak untuk dilakukan peletakan jack-up baik itu dari proses masuk dan lokasi peletakannya. Lokasi penelitian merupakan lokasi yang bersih (site clearance) karena tidak ditemukan halangan yang cukup besar yang dapat menghambat proses masuknya jack-up kedalam daerah penelitian tersebut.

Secara umum, lokasi penelitian bersih dari reruntuhan kapal/pesawat, debris, pockmark, mound dan shallow gas. Selain itu juga tidak ditemukan waterflow, mud flow, rock outcrop ataupun ranjau seperti yang dijelaskan pada Tabel 3. berikut.

Tabel 3. Analisa Kelayakan Lokasi Rencana Jack-Up Drilling Rig

\begin{tabular}{|c|c|c|c|c|}
\hline \multirow[b]{2}{*}{ No } & \multicolumn{4}{|c|}{ Jumlah Objek } \\
\hline & Objek & 营 & 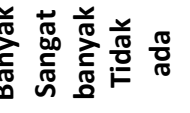 & Keterangan \\
\hline 1. & $\begin{array}{c}\text { Pipa/kabel bawah } \\
\text { laut }\end{array}$ & $\checkmark$ & & Layak \\
\hline 2. & $\begin{array}{c}\text { Bangkai } \\
\text { kapal/pesawat }\end{array}$ & & $\checkmark$ & Layak \\
\hline 3. & $\begin{array}{l}\text { Debris } \\
\text { Pockmark }\end{array}$ & & $\checkmark$ & Layak \\
\hline 4. & $\begin{array}{l}\text { (pockmark } \\
\text { cluster) }\end{array}$ & & $\checkmark$ & Layak \\
\hline 5. & Mound & & $\checkmark$ & Layak \\
\hline 6. & $\begin{array}{c}\text { Shallow gas, } \\
\text { waterflow }\end{array}$ & & $\checkmark$ & Layak \\
\hline 7. & Rock outcrop & & $\checkmark$ & Layak \\
\hline 8. & Mud flow & & $\checkmark$ & Layak \\
\hline 9. & Sedimen & $\checkmark$ & & Layak \\
\hline 10. & Ranjau & & $\checkmark$ & Layak \\
\hline
\end{tabular}

Adapun beberapa hal penting yang harus tetap diperhatikan bahwa pada lokasi tersebut terdapat cukup banyak jack-up footprint serta adanya pipa bawah laut yang membentang dari utara hingga 
ke selatan pada sisi barat lokasi penelitian. Selain itu juga ditemukan beberapa area dimana pada area tersebut terdapat sedimen dengan reflektor yang cukup kuat, sehingga dapat diinterpretasikan sebagai sedimen kasar (coarse sediment).

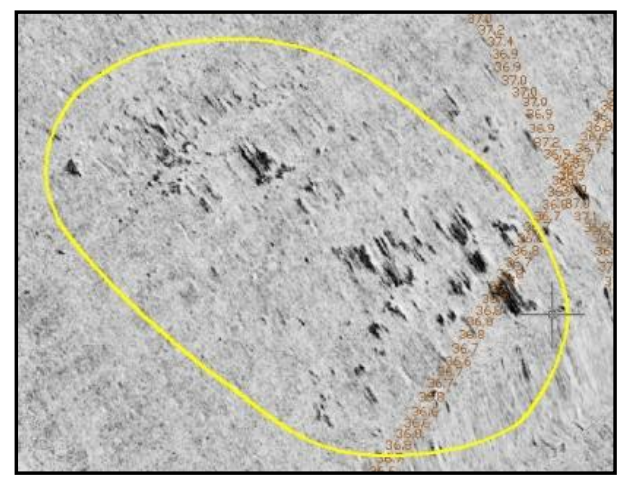

Gambar 6. Sedimen Kasar (Coarse Sediment)

Selain hal tersebut diatas, juga perlu diperhatikan bahwa pada lokasi tersebut terdapat banyak garukan (seabed scar) yang berasal dari goresan kaki jack-up yang sudah pernah masuk sebelumnya. Akan tetapi hal tersebut tidak terlalu berpengaruh terhadap proses masuknya jack-up drilling rig selanjutnya karena dimensinya tidak terlalu besar. Pada Gambar 3.5 merupakan salah satu contoh garukan kaki jack-up drilling rig pada permukaan dasar laut di sekitar lokasi platform.

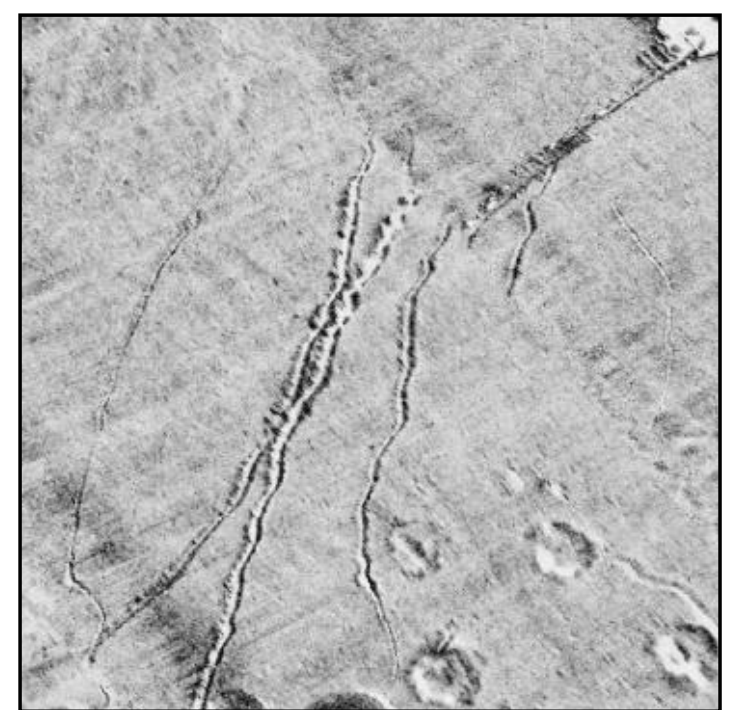

Gambar 7. Garukan / Cakaran (Seabed scar) pada Permukaan Dasar Laut yang Disebabkan oleh Kaki Jack-Up Drilling Rig
Berdasarkan analisa kriteria kelayakan permukaan dasar laut (seabed surface) untuk peletakan jackup drilling rig yang dilakukan, maka dapat direkomendasikan bahwa daerah penelitian tersebut merupakan daerah yang masih layak untuk dilakukan peletakan jack-up drilling rig.

\section{KESIMPULAN dan SARAN}

\section{Kesimpulan}

Kesimpulan yang dapat diambil dari penelitian tentang studi kelayakan rencana lokasi peletakan jack-up drilling rig menggunakan hasil pencitraan side scan sonar adalah sebagai berikut :

1. Lokasi rencana peletakan jack-up drilling rig dapat dikatakan masih layak untuk masuknya jack-up drilling rig jika ditinjau dari permukaan dasar laut.

2. Jack-up drilling rig hendaknya masuk melalui sisi timur dari platform, hal tersebut dilakukan untuk menghindari pipa bawah laut yang ada di sebelah barat platform.

3. Pada daerah penelitian terdapat cukup banyak jack-up footprint, sehingga perlu diwaspadai letak posisi dan kedalamannya agar tidak membahayakan proses peletakan jack-up drilling rig.

4. Selain jack-up footprint, juga ditemukan banyak goresan pada permukaan dasar laut, pipa bawah laut, serta sedimen yang cukup keras (coarse sediment).

5. Kondisi permukaan dasar laut daerah penelitian tersebut sebagian besar didominasi dengan tanah lempung atau lanau.

\section{Saran}

Saran yang dapat diberikan pada proses pengerjaan Tugas Akhir ini adalah sebagai berikut:

1. Untuk penelitian berikutnya disarankan menggunakan data multibeam echosounder (MBES) karena data tersebut dapat menggambarkan kondisi dipermukaan dasar laut secara menyeluruh sehingga obyek-obyek didasar laut dapat diketahui posisi $(X, Y)$ dan ketinggian atau kedalamannya (Z).

2. Hasil interpretasi citra side scan sonar hendaknya di dukung dengan data sampel tanah pada permukaan dasar laut agar dapat 
digunakan untuk memverifikasi hasil interpretasi dari side scan sonar.

\section{DAFTAR PUSTAKA}

2005. Konsep Perancangan Struktur Offshore, <http://www.scribd.com/catur_nugraha/d/45884 546-Bab-I-B-Konsep-Perancangan-StructureOffshore>. Dikunjungi pada tanggal 7 Februari 2012, jam 13.09 WIB 2007. Jack-up Rig, <http:// www.ogem.ir/imageDetail.aspx?img_id=7>. Dikunjungi pada tanggal 25 Februari 2012, jam 13.56 WIB

2001. Odom Echotrac MKII Single Beam Echo Sounder, $<$ http:// www.odomhydrographic.com/products.php?actio $\mathrm{n}=$ view\&id=6>, Dikunjungi pada tanggal 1 April 2012, jam 13.55 WIB

2012. Side Scan Sonar, < http:// www. starfishsonar.com/technology/sidescan-sonar.htm >, Dikunjungi pada tanggal 12 April 2012, jam $04.30 \mathrm{WIB}$

Dinas Hidro-Oseanografi, 2010. Data Pasang Surut Tide Tables. Jakarta : Jawatan Hidro Oseanografi TNIAL.

Australia, Geoscience Australia. 2012. Side Scan Sonar., <http://www.ozcoasts.gov.

au/geom_geol/toolkit/Tech_CA_sss.jsp >.

Dikunjungi pada tanggal 31 Maret 2012, jam 17.36 WIB

Badan Koordinasi Survey dan Pemetaan Nasional.2012. Peta Provinsi, <http:// www.bakosurtanal.go.id/bakosurtanal/petaprovinsi>. Dikunjungi pada tanggal 14 Januari 2013, jam 05.34 WIB

Cahyono, A. B., Handayani, H. H. 2005. Petunjuk Praktikum Fotogrametri I. Surabaya : Teknik Geodesi ITS.

Dharma, V.C.A. 2008. Interpretasi Hasil Pencitraan Side Scan Sonar pada Survai Penggelaran Kabel Bawah Laut. Surabaya : Teknik Geomatika.

Djunarsjah, E., Poerbandono. 2005. Survei Hidrografi. Bandung : Refika Aditama.
Gaudin, C., Cassidy, M.J., Bienen, B., Hossain, M.S. 2011. "Recent contributions of geotechnical centrifuge modelling to the understanding of jackup spudcan behavior".<http//www.sciencedirect.com/science /article/pii/S0029801810002714)> Australia : University of Western Australia.

Hancox, Michael. 1993. Jack-up moving : Volume II, Inggris.

Ingham, A.E. 1975. Sea Surveying. London : John Wiley and Sons.

International Hydrographic Organization. 2006. IHO Standards for Hydrographic Surveys, International Hydrographic Organization, Special Publication No 44, 4th Edition.

Lekkerkerk, $\mathrm{H}$ et al. 2006. Handbook of Offshore Surveying :Book Two, London.

Pageo Utama. 2012. Hasil Rekaman Side Scan Sonar.Jakarta

Pasek, I Made Royn. 2009. Survei Kelautan. <http://www.ilmukelautan.com/sig-dan penginderaan-jauh/pemetaan-sumberdayakelautan/426-survei-kelautan>. Dikunjungi pada tanggal 20 Juli 2011, jam 13.53 WIB

PPL.2006."What is the Jack-up Rig". Singapore : Shipyard Pte Ltd

Pratama, Pandu Y. 2008. Optimasi Jalur Terbaik Kabel Bawah Laut dari Perspektif Kehidrografian. Surabaya : Teknik Geomatika

Pusat Pemetaan Dasar Kelautan dan Kedirgantaraan. 2004. "Norma Pedoman Prosedur Standar dan Spesifikasi (NPPSS)". Bogor : Bakosurtanal.

Reddy, D.V., dan Arockiasamy, M. 1991. Offshore Structures: Volume 1. Florida : Krieger Publishing Company

Rose Mond Engineering Management Coorporation. 2010. "Jack-Up Drilling Unit". Iran

Schock, S.G., Tellier,A., Wulf, J., Sara, J. And Ericksen, M., Oktober. 2001. "Buried Object Scanning Sonar", IEEE Journal of Oceanic Engineering, 26,4.

Soegiono, 2004. Teknologi Produksi dan Perawatan Bangunan Laut. Surabaya : Airlangga University Press. 